\title{
Pengaruh Konsentrasi Doping terhadap Intensitas Emisi Material Luminisensi ZnO:Zn
}

\author{
Diky Anggoro, ${ }^{*}$ Rizki Yuniasari, Hasto Sunarno, dan Faridawati \\ Departemen Fisika-FIA, Institut Teknologi Sepuluh Nopember, Kampus ITS Sukolilo, Surabaya 60111
}

\begin{abstract}
Intisari
Material luminisensi $\mathrm{ZnO}$ (Zinc Oxide) telah disintesis menggunakan metode solution phase. Proses kalsinasi dilakukan pada temperatur $800^{\circ} \mathrm{C}$. Dilakukan identifikasi fasa, karakterisasi optik, dan intensitas luminisensi yang dihasilkan oleh $\mathrm{ZnO}$ hasil sintesis. Penambahan doping dilakukan dengan menggunakan variasi konsentrasi doping $1 \%$, 3\%, dan $5 \%$ dengan temperatur kalsinasi $300^{\circ} \mathrm{C}$ untuk mendapatkan ZnO:Zn. Dilakukan identifikasi fasa dan karakterisasi optik untuk ketiga sampel yang dihasilkan. Intensitas luminisensi diuji untuk mengetahui pengaruh penambahan konsentrasi doping terhadap emisi yang dihasilkan oleh material luminisensi $\mathrm{ZnO}: \mathrm{Zn}$. Diperoleh hasil material luminisensi yang memancarkan emisi hijau dengan rentang panjanggelombang $510 \mathrm{~nm}$ hingga $535 \mathrm{~nm}$. Semakin tinggi konsentrasi doping akan semakin banyak aktifator (doping) dalam host $(\mathrm{ZnO})$ yang menyerap energi untuk proses eksitasi sehingga semakin tinggi pula intensitas emisi yang dipancarkan.
\end{abstract}

\begin{abstract}
The luminance of Zinc Oxide materials has been synthesized using the phase solution method. The calcination process is carried out at a temperature of $800^{\circ} \mathrm{C}$. Performed phase identification, optical characterization, and luminance intensity generated by $\mathrm{ZnO}$ synthesis results. Addition of doping was done by using doping concentration of $1 \%, 3 \%$, and $5 \%$ with a calcination temperature of $300^{\circ} \mathrm{C}$ to obtain $\mathrm{ZnO}$ : $\mathrm{Zn}$. We do phase identification and optical characterization of the three samples produced. The intensity of luminescence was tested to determine the effect of adding doping concentrations to the emissions produced by luminance materials $\mathrm{ZnO}$ : Zn. Obtained luminance material results emit green emissions with $510 \mathrm{~nm}$ to $535 \mathrm{~nm}$ wavelength range. The higher the doping concentration will be the more activators (doping) in the host ( $\mathrm{ZnO}$ ) that absorbs the energy for the excitation process so that the higher emission intensity emitted.
\end{abstract}

KATA KUNCI: Luminisensi, zinc oxide, solution phase http://dx.doi.org/10.12962/j24604682.v14i1.3554

\section{PENDAHULUAN}

Cahaya merupakan salah satu energi yang sangat dibutuhkan. Berkaitan dengan hal ini, light emitting diodes (LED) sedang hangat diperbincangkan sebagai lampu hemat energi dengan efisien tinggi dan ramah terhadap lingkungan sebagai pengganti lampu konvensional.Seng oksida $(\mathrm{ZnO})$ memiliki potensi sebagai bahan photoluminescent yang setara dengan Gallium Nitrite (GaN) untuk digunakan dalam aplikasi LED [1]. Penelitian ini bertujuan untuk mengetahui sifat luminisen $\mathrm{ZnO}: \mathrm{Zn}$ dan pengaruh konsentrasi doping pada sifat luminisen yang dihasilkan oleh $\mathrm{ZnO}: \mathrm{Zn}$. Seng oksida memiliki emisi luminisensi berwarna biru hingga hijau-kuning yang cukup efisien. Senyawa ini memiliki struktur kristal dan band gap yang hampir sama dengan GaN $[1,2]$. Seng oksida merupakan material yang relatif tidak beracun, murah, melimpah, memiliki sifat optik yang baik, dan biaya produksi yang rendah bila dibandingkan dengan Cadmium Sulfide (CdS) dan Gallium Nitrite (GaN) [1, 3].

Senyawa ini juga mempunyai sifat-sifat yang mengun-

\footnotetext{
*E-MAIL: anggoro@physics.its.ac.id
}

tungkan seperti transparansi yang baik, mobilitas elektron tinggi, dan luminisen pada suhu kamar yang kuat. Sifat ini menjadikan seng oksida sebagai material yang potensial bagi pengembangan sumber cahaya lampu hemat energi [1, 4 ].

Studi mengenai sifat luminisensi yang dihasilkan oleh $\mathrm{ZnO}$ yang di-doping dengan $\mathrm{Zn}$ [2]. Hasil penelitian tersebut menunjukkan bahwa material luminisensi $\mathrm{ZnO}: \mathrm{Zn}$ memiliki pancaran emisi luminisensi hijau yang baik $[2,5]$. Pada penelitian ini dilakukan sintesis material luminisensi $\mathrm{ZnO}: \mathrm{Zn}$ untuk mengetahui intensitas luminisensi yang dihasilkan dan dilakukan variasi konsetrasi doping untuk mengetahui pengaruhnya terhadap intensitas luminisensi yang dihasilkan oleh material $\mathrm{ZnO}: \mathrm{Zn}$.

Secara umum material luminisensi terdiri dari host (matriks) dan doping atau luminiscnent center (aktifator). Host adalah tempat aktifator berada, sedangkan aktifator merupakan impuritas atom dalam jumlah kecil yang terdistribusi di dalam host [2, 6]. Proses luminisensi terjadi sebagai berikut. Radiasi eksitasi diabrsobrsi oleh aktifator, menyebabkan elektron aktifator naik ke ground ke keadaan tereksitasi [7]. Dari keadaan tereksitasi tersebut, ion aktifator kembali ke keadaan dasar dan menghasilkan emisi dan radiasi. Material luminisensi hanya akan memancarkan radiasi elektromagnetik bila energi yang diberikan untuk eksitasi diabr- 


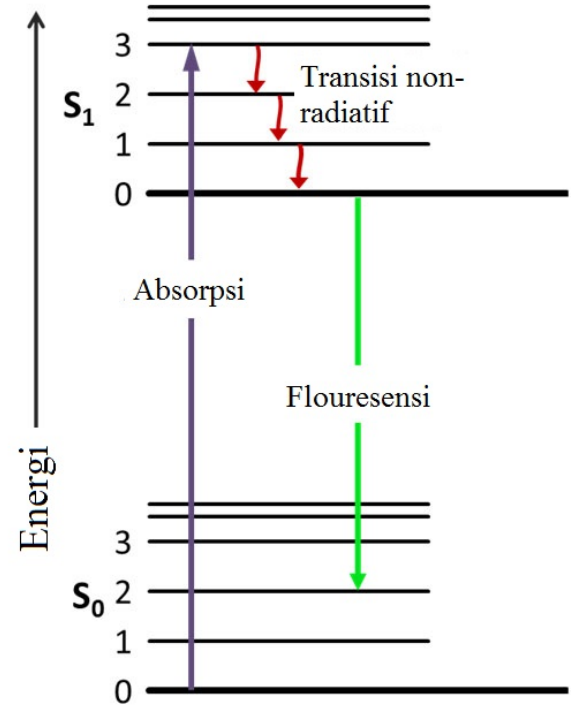

Tingkat dasar

Gambar 1: Proses luminisensi cahaya hijau.

sorbsi oleh aktifator pada host.

Syarat terjadinya eksitasi pada ion aktifator adalah energi yang diabrsorbsi minimal sama dengan energi gapnya. Dengan demikian, aktifator akan tereksitasi dari tingkat energi tertinggi pada keadaan ground state menuju tingkat energi vibrasi terendah dari keadaan tereksitasi. Pada pita energi direct, proses turunnya kembali elektron dari tingkat eksitasi (konduksi) menuju tingkat valensi akan langsung terjadi dikarenakan pita valensi dan pita konduksi terletak pada kesetimbangan momentum yang sama $[5,8,9]$.

Penyinaran $\mathrm{ZnO}$ dengan sinar ultraviolet atau berkas elektron yang energinya lebih besar dari lebar celah pita energi menyebabkan elektron meloncat ke pita konduksi membentuk elektron bebas pada pita konduksi dan hole bebas pada pita valensi. Terlihat pada Gambar 1, sebagai gambaran bahwa elektron dan hole bebas tidak stabil dan seketika membentuk pasangan elektron dan hole atau eksiton. Hal ini ditandai dengan munculnya tingkat energi eksiton yang letaknya sedikit dibawah tepi pita konduksi. Sebagian eksiton dapat musnah atau teranihilasi yaitu elektron dari tingkat energi eksiton kembali ke pita valensi disertai denganpemancaran spektrum luminisen hijau-biru [5, 8, 10].

\section{METODE PENELITIAN}

Langkah awal dalam penelitian ini yaitu menyiapkan peralatan yang dibutuhkan. Sintesis dimulai dengan melarutkan zinc acetate dehydrate kedalam aquadess ebanyak $100 \mathrm{ml}$, kemudian diaduk menggunakan magnetic stirrer pada temperatur $100 \mathrm{oC}$. Selanjutnya, Polyethylene Glycol 4000 den- gan perbandingan 2:1 terhadap zinc acetate dehydrate dimasukkan sedikit demi sedikit kedalam larutan. Proses stirring dilakukan selama kurang lebih 3 jam hingga larutan menjadi kental. Larutan yang telah mengental kemudian dikalsinasi dengan temperature $800^{\circ} \mathrm{C}$. Hasil yang diperoleh dari kalsinasi ini adalah seng oksida $(\mathrm{ZnO})$ berupa serbuk [4 ].

Serbuk ZnO yang telah dihasilkan kemudian di-doping dengan serbuk zinc actate dihydrate sebanyak 1\%, 3\%, dan 5\% melalui pencampuran mekanik selama 1 jam kemudian dilakukan kalsinasi pada temperatur $300^{\circ} \mathrm{C}$. Hasil yang diperoleh dari kalsinasi ini adalah $\mathrm{ZnO}: \mathrm{Zn}$ berupa serbuk yang kemudian akan diuji fasa menggunakan X ray Diffractometer(XRD). Selain bertujuan untuk mengetahui fasa yang terbentuk dari material hasil sintesis, hasil dari pengujian ini juga digunakan untuk menghitung ukuran partikel menggunakan Scherrer formula

$$
D=\frac{k \lambda}{\beta \cos \theta}
$$

dengan D adalah ukuran kristal, $\mathrm{k}$ adalah shape factor $(0,89)$, $\lambda$ yaitu 1,54 $\ddot{\mathrm{A}}, \theta$ adalah sudut Bragg, dan $\beta$ adalah FWHM (Full-Width at Half Maximum). Setelah pengujian fasa kemudian dilakukan pengujian karakteristik optik menggunakan UV-Vis Spektrofotometer, serta dilakukan pengujian intensitas luminisensi yang dihasilkan oleh material $\mathrm{ZnO}: \mathrm{Zn}$ menggunakan Photoluminescence Spectrometer.

\section{HASIL DAN DISKUSI}

\section{Analisis fasa $\mathrm{ZnO} \mathbf{Z n}$}

Dari proses sintesis yang telah dilakukan diperoleh $\mathrm{ZnO}$ berupa serbuk. Selanjutnya, dilakukan uji XRD (X-Ray Diffraction) untuk mengetahui fasa yang terkandung di dalam material luminisensi $\mathrm{ZnO}: \mathrm{Zn}$.

Data yang diperoleh dari hasil uji XRD kemudian diolah menggunakan software Match! untuk mengetahui fasa yang terbentuk. Berdasarkan hasil analisis mengunakan software Match! pola difraksi sinar X yang terlihat mempunyai fasa $\mathrm{ZnO}$ seperti yang terlihat pada Gambar 2. Puncak-puncak yang terlihat pada hasil XRD sesuai dengan data referensi $\mathrm{ZnO}$ dimana terdapat puncak-puncak pada sudut 31,$68 ; 34,35$ ; 36,17; 47,47 ; 56,52 ; 62,80. Selanjutnya dilakukan analisis ukuran kristal menggunakan Scherer formula dimana $\beta$ adalah FWHM (Full-Width at Half Maximum), $2 \theta$ adalah sudut Bragg, k adalah shape factor $(0,89), \lambda$ yaitu 1,54 $\ddot{A}$, dan $\mathrm{D}$ adalah ukuran kristal. Dari hasil perhitungan diperoleh hasil rata-rata ukuran kristal yaitu sebesar 139,5 nm.

\section{Analisis karakteristik optik ZnO:Zn}

Karakterisasi sifat optik dari $\mathrm{ZnO}: \mathrm{Zn}$ dilakukan dengan pengujian UV-Vis Spectrofotometer, dimana pengujian dilakukan pada panjang gelombang 200 hingga $800 \mathrm{~nm}$ untuk mengetahui absorbansi dan transmitansi dari ZnO:Zn. Spektrum absorbansi dari $\mathrm{ZnO}: \mathrm{Zn}$ ditunjukkan pada Gambar 3. Absorbansi cahaya oleh suatu material merupakan bentuk in- 


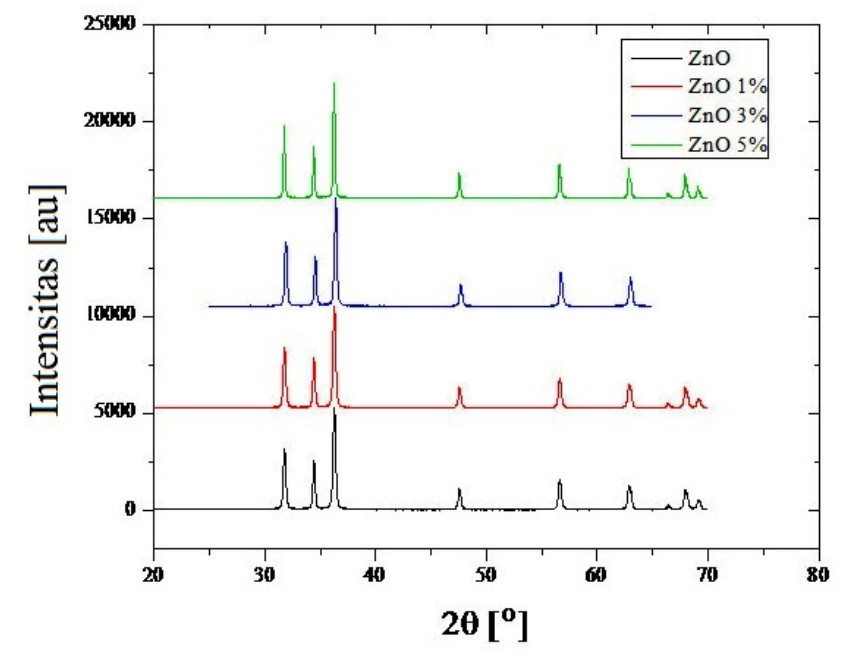

Gambar 2: Pola XRD material luminisensi ZnO:Zn.

teraksi gelombang cahaya dan atom molekulnya. Energi cahaya diserap oleh atom dan digunakan oleh atom tersebut untuk bertransisi ke tingkat energi yang lebih tinggi (eksitasi). Kurva hasil uji absorbansi menunjukkan absorbansi $\mathrm{ZnO}: \mathrm{Zn}$ dengan konsentrasi doping 5\% memiliki intensitas yang lebih baik dibandingkan dengan $1 \%$ dan 3\%. Absorbansi tersebut terletak pada rentang panjang gelombang UV 200nm hingga $300 \mathrm{~nm}$.

Pada material luminisen, $\mathrm{ZnO}$ berperan sebagai host dan doping berperan sebagai aktifator. Radiasi eksitasi akan diabsorbsi oleh aktifator (doping) yang akan menyebabkan elektron naik dari keadaan dasar kekeadaan tereksitasi. Ini menyebabkan terbentuknya elektron bebas pada pita konduksi dan hole bebas pada pita valensi. Dari keadaan tereksitasi elektron akan kembali kekeadaan dasar dengan memancarkan panas dan emisi.

\section{Analisis sifat luminisensi ZnO:Zn}

Hasil pengujian photoluminescence spectrophotometer menunjukkan bahwa $\mathrm{ZnO}: \mathrm{Zn}$ memiliki intensitas eksitasi yang baik pada panjanggelombang $240 \mathrm{~nm}$ dan pancaran emisi yang termasuk dalam rentang panjanggelombang cahaya hijau yaitu $510 \mathrm{~nm}$ hingga $535 \mathrm{~nm}$ dengan intensitas tertinggi terletak pada panjanggelombang $523 \mathrm{~nm}$ dan untuk transfer energi non-radiatif ke 3P1, dan lebih jauh lagi ke 1S0, menghasilkan transisi radiasi dari 1P1 ke 1S0 berupa emisi biru dan untuk emisi hijau disebabkan oleh transisi radiasi 1S0 ke 3P1.

Penambahan doping (aktifator) dapat mempengaruhi pancaran emisi yang dihasikan oleh $\mathrm{ZnO}$. Variasi konsentrasi doping yaitu $1 \%, 3 \%$, dan 5\% digunakan untuk mengetahui pengaruh doping terhadap pancaran emisi yang dihasilkan.

Pada Gambar 4 menunjukkan kurva transmitansi $\mathrm{ZnO}: \mathrm{Zn}$. Hasil uji transmitansi menunjukkan transmitansi yang paling rendah yaitu $\mathrm{ZnO}: \mathrm{Zn}$ dengan konsentrasi doping 5\% yang terletak pada rentang panjanggelombang 200nm hingga 300nm. Rendahnya tranmitansi pada $\mathrm{ZnO}: \mathrm{Zn}$ dengan konsentrasi doping 5\% disebabkan oleh tingginya absorbansi sehingga cahaya

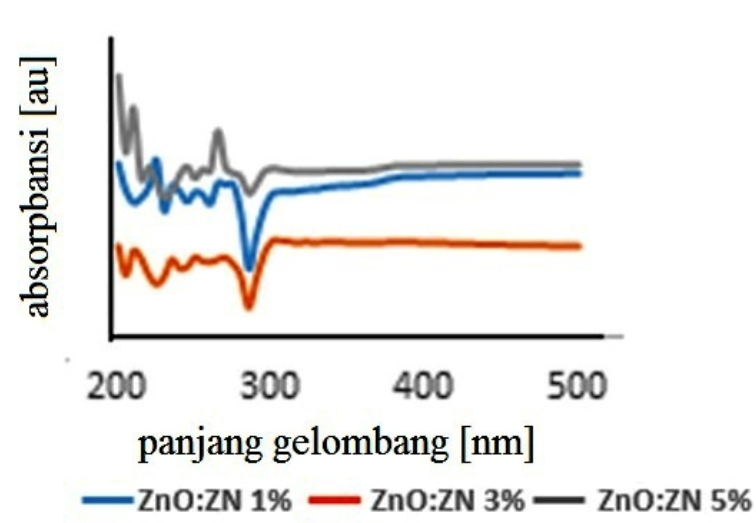

Gambar 3: Spektrum absorbansi $\mathrm{ZnO} \mathrm{Zn}$ dengan variasi konsentrasi doping $1 \%, 3 \%, 5 \%$.

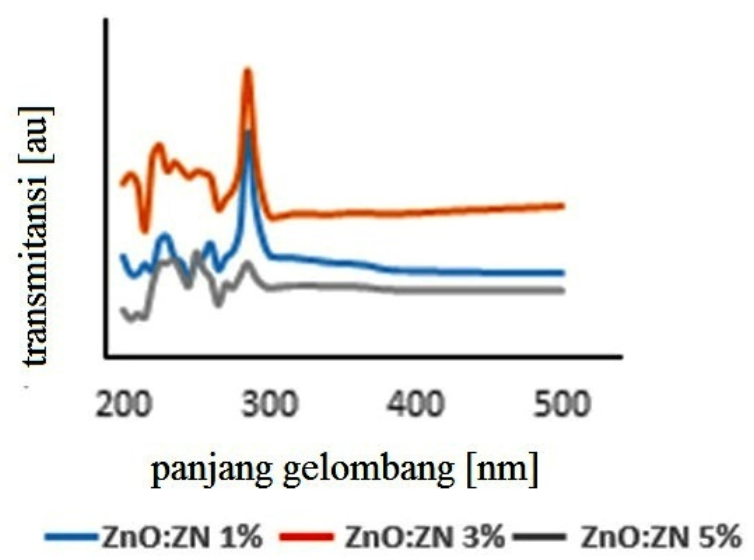

Gambar 4: Spektrum transmitansi $\mathrm{ZnO}: \mathrm{Zn}$ dengan variasi konsentrasi doping $1 \%, 3 \%, 5 \%$.

akan lebih banyak terserap dan cahaya yang dilewatkan menjadi lebih sedikit.

Gambar 5 menunjukkan bahwa semakin tinggi konsentrasi doping maka semakin tinggi pula intensitas emisinya. $\mathrm{ZnO}: \mathrm{Zn}$ dengan doping $5 \%$ memiliki intensitas emisi yang paling tinggi dibandingkan $\mathrm{ZnO}$ dengan doping 1\%, 3\%, dan tanpa doping. Hal ini disebabkan karena semakin besar konsentrasi doping maka aktifator dalam host akan semakin banyak sehingga radiasi eksitasi yang diabsorbsi oleh aktifator (doping) akan semakin besar. Absorbansi terjadi pada saat foton masuk bertumbukan dengan atom-atom material dan menyerahkan energinya pada elektron atom. Foton mengalami perlambatan dan akhirnya berhenti. Absorbansi dari energi cahaya dapat menyebabkan elektron tereksitasi ketingkat energi yang lebih tinggi. Elektron yang terlepas meninggakan pita valensi menuju ke pita konduksi. Semakin banyak aktifator (doping) dalam host maka akan semakin banyak pula elektron yang naik kekeadaan tereksitasi dan ketika elektron kembali kekeadaan dasar akan menghasilkan pancaran luminisensi yang kuat. 


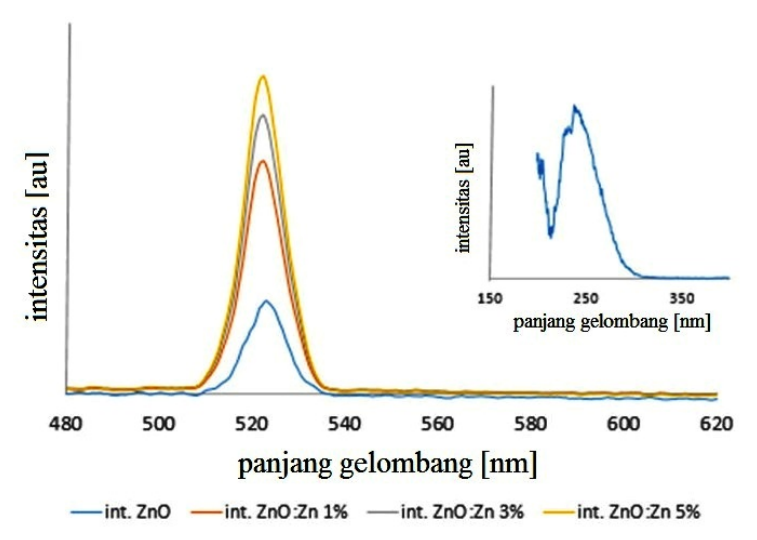

Gambar 5: Intensitas luminisen $\mathrm{ZnO}$ dengan doping 1\%, 3\%, 5\%, dan tanpa doping.

\section{SIMPULAN}

Material Luminisensi $\mathrm{ZnO}: \mathrm{Zn}$ memiliki intensitas eksitasi yang baik pada panjang gelombang 240nm dan emisi luminisensi yang terletak pada rentang panjanggelombang cahaya hijau yaitu 510nm hingga 535nm dengan intensitas tertinggi terletak pada panjanggelombang $523 \mathrm{~nm}$. Konsentrasi doping berpengaruh terhadap intensitas emisi material luminisensi $\mathrm{ZnO}: \mathrm{Zn}$ yaitu semakin tinggi konsentrasi doping semakin tinggi pula intensitas emisi luminisensinya yang disebabkan oleh semakin banyak aktifator dalam host yang mengabsorbsi radiasi eksitasi dan menyebabkan semakin banyak elektron yang tereksitasi sehingga pancaran luminisensi yang dihasilkan semakin kuat pada saat elektron berelaksasi ke ground state dari posisi tereksitasi.
[1] C. Panatarani, D. Anggoro, and F. Faizal, "Solution Phase Synthesis and Photoluminescent Properties of Nanocrystal $\mathrm{LaPO}_{4}$ : $\mathrm{Eu}_{3}^{+}$, pp. 77-80, 2010.

[2] C. Jagadish, and S. Pearton (Ed)., "Zinc Oxide Bulk, Thin Film and Nanostructures", Elsevier., 2006.

[3] Chorkendroff, I. and J. W. Niemantsverdriet, "Concept of Modern Catalysis and Kinetics", Wiley-VCH GmbH \& Co. New York, 2003.

[4] Putri, "Sintesis dan Karakterisasi Nanopartikel Zinc Oxide ( $\mathrm{ZnO})$ dengan Menggunakan Metode Sol-Gel Berdasarkan Variasi pH", Skripsi S1, Fakultas Sains danTeknologi, Airlangga, Surabaya, 2011.

[5] G. Blasse, dan B.C Grabmaier, "Luminescent Materials", Springer, 1994.

[6] S. Chakraborty and P. Kumbhakar, "Effect of polyethylene glycol on the particle size and photoluminescence emissions characteristics of chemically synthesized $\mathrm{ZnO}$ nanoparticles", Opt.
Commun., vol. 318, pp. 61-66, 2014

[7] P.S. Gupta, Nandha Shakti, "Structural and Optical Properties of Sol-gel Prepared ZnO Thin Film", Applied Physics Research, vol. 2, no.1, May 2010, Department of Applied Physics, Indian School of Mines.

[8] C. H. Zang, D. M. Zhang, C. J. Tang, S. J. Fang, Z. J. Zong, Y. X. Yang, C. H. Zhao, and Y. S. Zhang, "Optical Properties of a ZnO / P Nanostructure Fabricated by a Chemical Vapor Deposition Method" pp. 1852-18530, 2009.

[9] M. A. Tsahabalala, B. F. Dejene, H.C. Swart, ”Synthesis and Characterization of $\mathrm{ZnO}$ Nanoparticle using Polyethylene Glycol (PEG)", South Africa: University of the Free Stat, 2012.e

[10] M. A. Tshabalala, B. F. Dejene, and H. C. Swart, "Synthesis and characterization of $\mathrm{ZnO}$ nanoparticles using polyethylene glycol (PE )", Phys. B Phys. Condens. Matter, vol. 407, no. 10, pp. 1668-1671, 2012. 